\title{
Comparative Study of Histological Alterations in Intravascular Catheter Region with and without the Use of Local Corticosteroid
}

\author{
Carolina Utsunomiya Muniz'1, Maíra Stathourakis Sampaio Amaral', Neil Ferreira Novo², \\ Juliana Abeche Fermozelli3 ${ }^{3}$, Willy Marcus França ${ }^{4^{*}}$ \\ ${ }^{1}$ Medical Science and Health Faculty, Sao Paulo, Brazil \\ ${ }^{2}$ Department of Medicine-Service of Statistical Studies, Sao Paulo, Brazil \\ ${ }^{3}$ Department of Morphology \& Pathology, Sao Paulo, Brazil \\ ${ }^{4}$ Department of Medicine and Pediatric Surgeon, Sao Paulo, Brazil \\ Email: *willy@drwilly.com.br
}

How to cite this paper: Muniz, C.U. Amaral, M.S.S., Novo, N.F., Fermozelli, J.A. and França, W.M. (2017) Comparative Study of Histological Alterations in Intravascular Catheter Region with and without the Use of Local Corticosteroid. Surgical Science, 8, 175-183.

https://doi.org/10.4236/ss.2017.84020

Received: February 23, 2017

Accepted: April 14, 2017

Published: April 17, 2017

Copyright $\odot 2017$ by authors and Scientific Research Publishing Inc. This work is licensed under the Creative Commons Attribution International License (CC BY 4.0).

http://creativecommons.org/licenses/by/4.0/

\begin{abstract}
Introduction: Central venous access is one of the most common procedures in pediatric surgery worldwide for infusion of antibiotics, electrolytes, chemotherapy, total parenteral nutrition, etc. Local regional complications due the permanence of venous catheters are described most frequently as: thrombosis, infection, edema and local cellulites, mobilization and catheter loss. As a result, the catheter must be prematurely removed. The use of local corticosteroid (Betamethasone) can be an alternative to lengthen the catheter maintenance. Aim: This study objective is to analyze perivascular inflammatory alterations in phlebotomies with polytetrafluoroethylene (20 GA) catheter in two periods of permanence 15 and 30 days with or without local Corticosteroid. Material \& Method: $32 \mathrm{New}$ Zealand adult rabbits were submitted to catheterization of the External Right Jugular Vein(RJV) and were divided in 4 groups: G1: with 8 rabbits' catheters collected in the $15^{\text {th }}$ day, without corticosteroid use; G2: with 8 rabbits' catheters collected in the $15^{\text {th }}$ day, with corticosteroid use; G3: with 8 rabbits' catheters collected in the $30^{\text {th }}$ day, without corticosteroid use; G4: with 8 rabbits' catheters collected in the $30^{\text {th }}$ day, with corticosteroid use; G5: Control was the contralateral vein of the rabbit itself. Results: G2 presented lower inflammatory incidence when compared to G1, despite this difference was not statistically significant $(p=0.7333)$. G4 also displayed lower inflammatory incidence than G3, however it was not statistically significant $(p=0.3571)$. When G1 and G3 were compared with G2 and $\mathrm{G} 4$, there was also lower incidence of the inflammatory process in those subjects using Betamethasone, although this difference was not statistically significant $(p=0.3202)$. Conclusion: Betamethasone used in the vascular cathe-
\end{abstract}


ters insertion areas through phlebotomy can lessen local inflammatory manifestations of venous catheterizations.

\section{Keywords}

Experimental Surgery, Central Venous Catheter, Venous Thrombosis, Phlebitis, Corticosteroid

\section{Introduction}

Central venous access, in spite of the high rate of complications, is broadly employed in pediatric neonatal intensive care unit in several surgical procedures [1] [2].

After a number of peripheral punctures, the superficial and peripheral vases had no conditions to sustain neither the catheter nor the presence of a number of infusion solutions, be those electrolytes, vasoactive drugs, prolonged parenteral nutrition or antibiotics [3].

Several complications have been described, not only in the moment of catheter insertion, but also during its permanence in the vein and its removal [4]. Lesions such as venous laceration, dissection of the venous wall and accidental arterial punction, pneumothorax, hematoma, and even death might occur at the moment of the catheter insertion [5] [6].

Endothelial injury, venous stasis, and hypercoagulability characterize the Virchow's triad (1856), are the contributors to thrombophlebitis and deep venous thrombosis (DVT). Moreover, both endothelial injury and venous stasis are the factors that trigger thrombotic process [6]. Endothelial trauma in turn starts coagulation chain reactions through three pathways: exposure of subendothelial tissue (collagen) activating tissual thromboplastin, release of tumor necrosis factor (TNF) and interleukin-1 (IL-1) by endothelium cells, and released toxins as the result of tissual necrosis or lesion [7] [8].

High numbers of cases of superficial thrombophlebitis cases occur due to chemical lesion of the vase intima by intravenous injections or infusions of different types of solutions and different concentrations with diagnosis or therapeutic objectives [9]. Mechanical factors that involve venous catheterization are also associated to this process, given that the catheter material, the insertion site and time of permanence are variables to be considered [10]. In the initial phase of thrombophlebitis, the vein and blood clot present predominance of leukocytic infiltrate (phlogistic agents). This inflammatory process spreads out to neighboring tissues, especially skin and subcutaneous cellular tissue, thus explaining the characterization of its clinical symptoms, as well as lower friability and greater thrombus consistency [11] [12].

A great variety of materials are used in catheter manufacturing; the most common are polytetrafluoroethylene (PTFE), polyurethane, silicone, polyamide and polyester. 
Treatment of inflammatory reaction of blood vessel and perivascular region is generally performed with the catheter removal and the need to perform new catheterization at another locality.

Corticosteroids usage such as Betamethasone, a potent anti-inflammatory agent acting as inhibitor of pro-inflammatory agents and some interleukins (IL-1, IL-6 e IL-10), can also act locally inhibiting inflammatory reactions described in the previous study [13].

The objective of the present study was to analyze inflammatory perivascular histological alterations in phlebotomies with polytetrafluoroethylene (20 GA) catheter for 15 and 30 days of permanence with or without local Corticosteroid.

\section{Material \& Method}

The current study was submitted to and approved by the FCMS-PUC/SP Commission of Ethics for Animals in Research Use (CEUA).

Thirty two New Zealand rabbits weighing approximately $2.5 \mathrm{~kg}$ were selected. On the experiment day, the rabbits were submitted to sedation with Ketamine base (40 - $50 \mathrm{mg} / \mathrm{kg}$ ) intramuscularly, associated with $1.5 \mathrm{ml}$ Xylazine (4 - 6 $\mathrm{mg} / \mathrm{kg}$ ) also injected intramuscularly. Local anesthesia was also provided with an injection of Bupivacaine solution at $0.5 \%$ without vasoconstrictor, which provides analgesia in the post-operatory period of approximately 2 - 3 hours.

The Right External Jugular Vein (RJV) was identified in the right cervical region, at approximately $4-5 \mathrm{~cm}$ below the submandibular line of the animal.RJV was isolated in the cranial and caudal direction with polypropylene 5 - 0 cord. Phlebotomy, the vein partial section, was performed with precision using a scalpel blade $\mathrm{N}^{\circ} 11$ to make an incision at $45^{\circ}$ toward the cranial direction which made the proximal edge more visible and facilitating the catheter introduction (Figure 1).

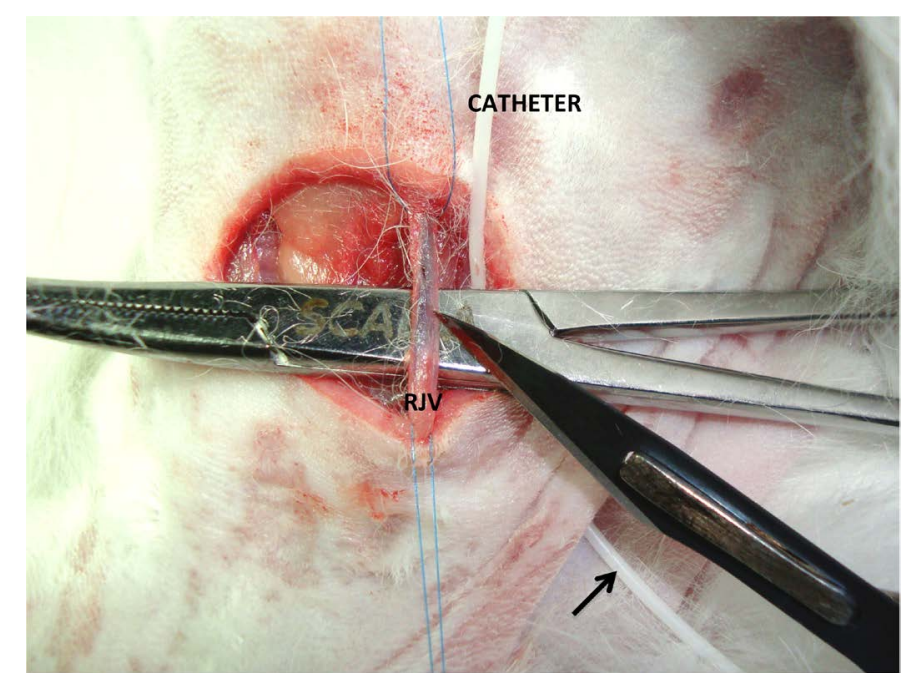

Figure 1. Image shows the oblique section of the exposed RJV supported by Polypropylene 5 - 0 . The arrow shows the counter-opening area through which the catheter is introduced in the skin towards the incision opening. 
PTFE (20 GA) catheter with an extension of approximately $5-6 \mathrm{~cm}$ was introduced next to the Right Atrium. The catheter is fixated with a 5 - 0 nylon cord in the vein and, distal ligature was done in the same vein to avoid blood extravasation. Immediately after catheterization of RJV, the catheter proximal external extremity was sectioned and the catheter was folded and connected with the same cord so to circumvent extravasation. The entire set was placed under the skin (Figure 2). Suture of the animal skin was performed with Nylon 5 - 0 with simple separated stiches.

The animals were divided in 5 groups:

Group 1: G1, group of 8 (eight) animals whose catheters were collected on the $15^{\text {th }}$ day postoperative, WITHOUT the use of corticosteroid;

Group 2: G2, group of 8 (eight) animals whose catheters were collected on the $15^{\text {th }}$ day postoperative, WITH the use of corticosteroid;

Group 3: G3, group of 8 (eight) animals whose catheters were collected on the $30^{\text {th }}$ day, WITHOUT the use of corticosteroid;

Group 4: G4, group of 8 (eight) animals whose catheters were collected on the $30^{\text {th }}$ day, WITH the use of corticosteroid;

Group 5: Control group composed of the contralateral vein of the rabbit itself.

The collection of materials was carried out in accordance to each group of animals. The catheterized RJV was removed leaving all the adipose tissue wrapped around it with a margin of at least $0.5 \mathrm{~cm}$ to contain the adjacent tissues, thus protecting the external vein and avoiding the inadvertent removal of the catheter (Figure 3). The block containing the vein, catheter and adjacent tissue was placed in a flask containing formol and stained with hematoxylin and eosin (HE).

Fisher Exact Test for small samples was performed to establish confidence interval below $5 \%(p<0.05)$.

\section{Results}

Thirty two rabbits were operated divided in groups of eight. One G3 animal and another in G4 died and were excluded from the study.

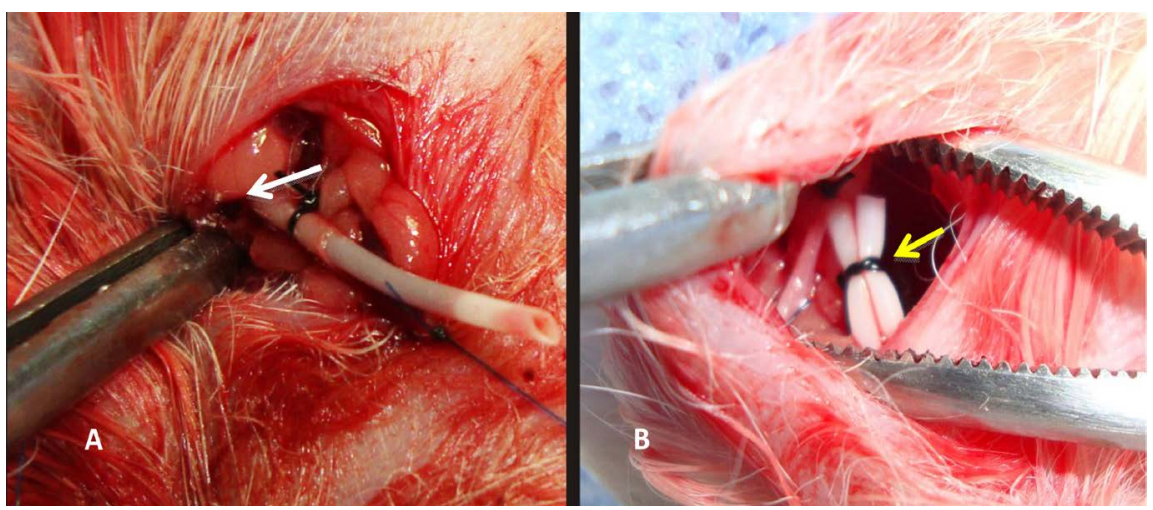

Figure 2. In (A) it is shown the catheter external extremity fixed with nylon 5 - 0 on RJV (white arrow) that will be folded and tied with nylon 5 - 0 cord to avoid over flowing, as in (B) (yellow arrow). 


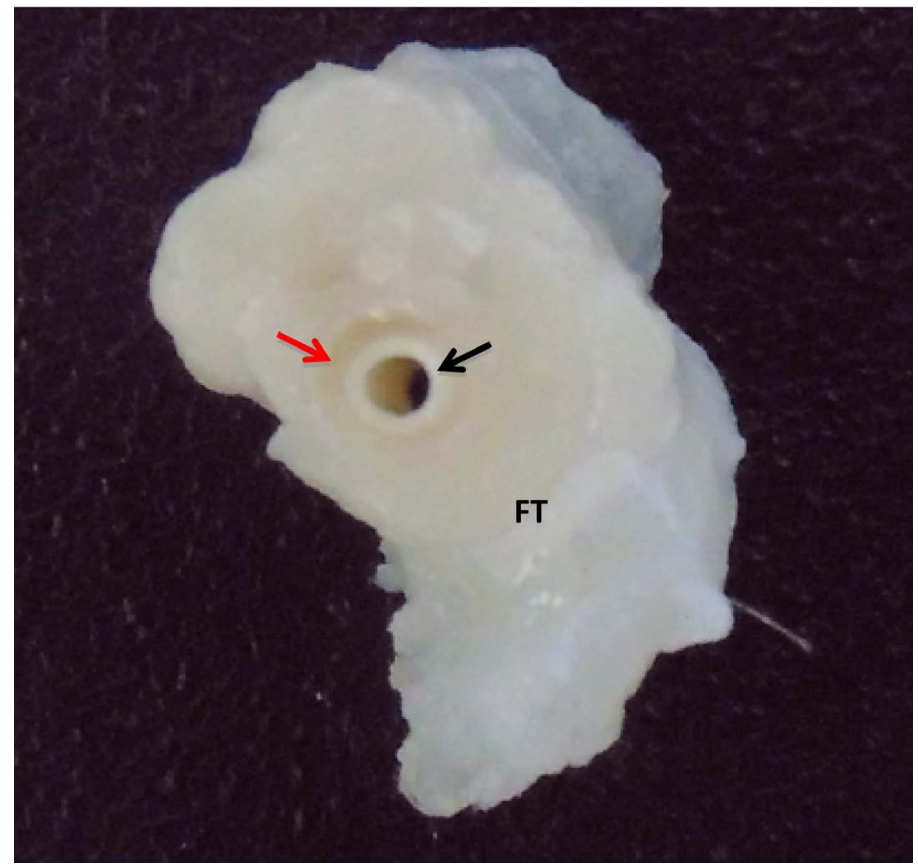

Figure 3. Shows the collected material that contains the vein (red arrow), and catheter (black arrow) and adjacent subcutaneous cellular tissue (CT).

Regarding the histological findings, it was observed the presence of lymphoplasmocitary infiltrate in 7 G1 animals, 6 G2 animals, 3 G3 animals and 2 G4 animals. There was no lymphoplasmocitary infiltrate in any material of G5 which was composed of RJV and the perivascular region of the same rabbit (Table 1).

In two G2 rabbits, the adjacent tissues contained a slight lymphoplasmocitary infiltrate with histiocytes and giant multinucleated cells (Figure 4).

In 2 rabbits endothelium was preserved, though tissue inflammation was observed. One of these rabbits presented the formation of a thrombus in the vascular lumen (Figure 5).

An animal in the G3 group presented a thrombus in its interior, as well as well as an animal in G4.

In G4, three rabbits presented preserved vascular walls and absence of inflammation in the adjacent tissues. In one sample, despite the preserved endothelium, it was observed fibrin developing in the vascular lumen and inflammation of soft tissues.

All G5 animals didn't present any inflammatory infiltrate in their adjacent tissues.

In the statistical analysis, the histological findings in each sample were only categorized as presence or absence of inflammation. Other findings, such as congested vases or thrombus formation weren't considered.

Any sample with inflammatory infiltrate in adjacent tissues was considered as inflammation.

When compared with the results between groups G1 $\times$ G3 in which corticosteroid wasn't used, there was no statistical differences with regards to the presence 
Table 1. Comparative statistic of the research groups.

\begin{tabular}{|c|c|c|c|c|c|c|c|}
\hline \multirow[b]{2}{*}{ Time } & \multicolumn{3}{|c|}{ No Corticosteroid $(\mathrm{G} 1 \times \mathrm{G} 3)$} & \multicolumn{3}{|c|}{ With Corticosteroid $(\mathrm{G} 2 \times \mathrm{G} 4)$} & \multirow[b]{2}{*}{ No $\times$ With } \\
\hline & Inflam. & $\begin{array}{c}\text { No } \\
\text { Inflam. }\end{array}$ & Total & Inflam. & $\begin{array}{c}\text { No } \\
\text { Inflam. }\end{array}$ & Total & \\
\hline 15 days & 7 & 1 & 8 & 6 & 2 & 8 & $\mathrm{p}=0.7333$ \\
\hline 30 days & 3 & 4 & 7 & 2 & 5 & 7 & $\mathrm{p}=0.3571$ \\
\hline Total & 10 & 5 & 15 & 8 & 7 & 15 & $\mathrm{p}=0.3202$ \\
\hline & & Fisher's Exact Test & & \multicolumn{3}{|c|}{ Fisher's Exact Test } & \\
\hline
\end{tabular}

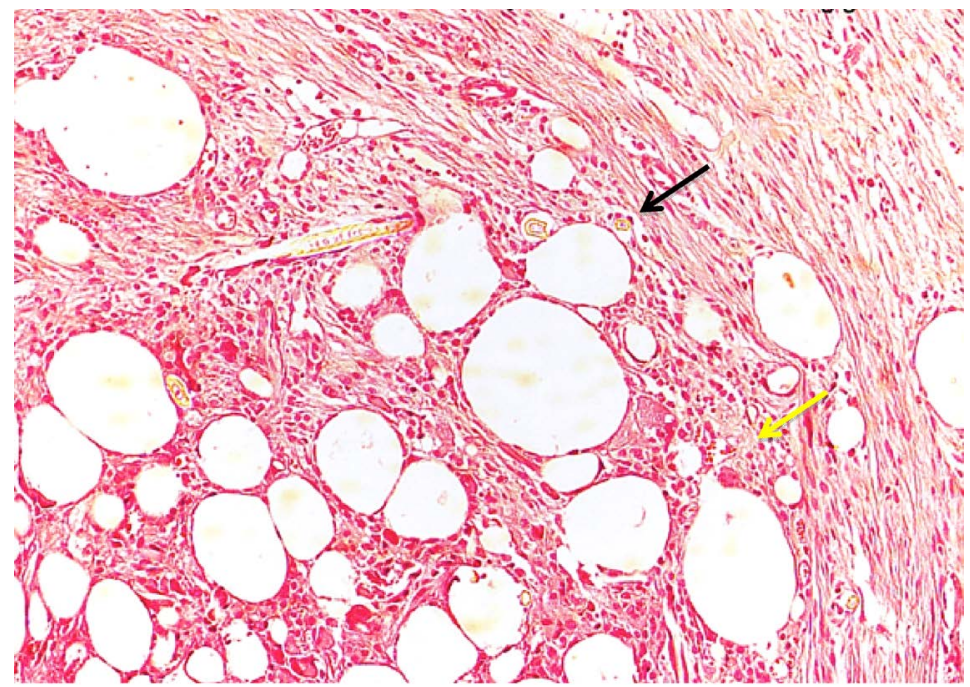

Figure 4. Shows in the G2 image slight lymphoplasmocitary infiltrate with histiocytes (black arrow) and giant multinucleated cells (yellow arrow).

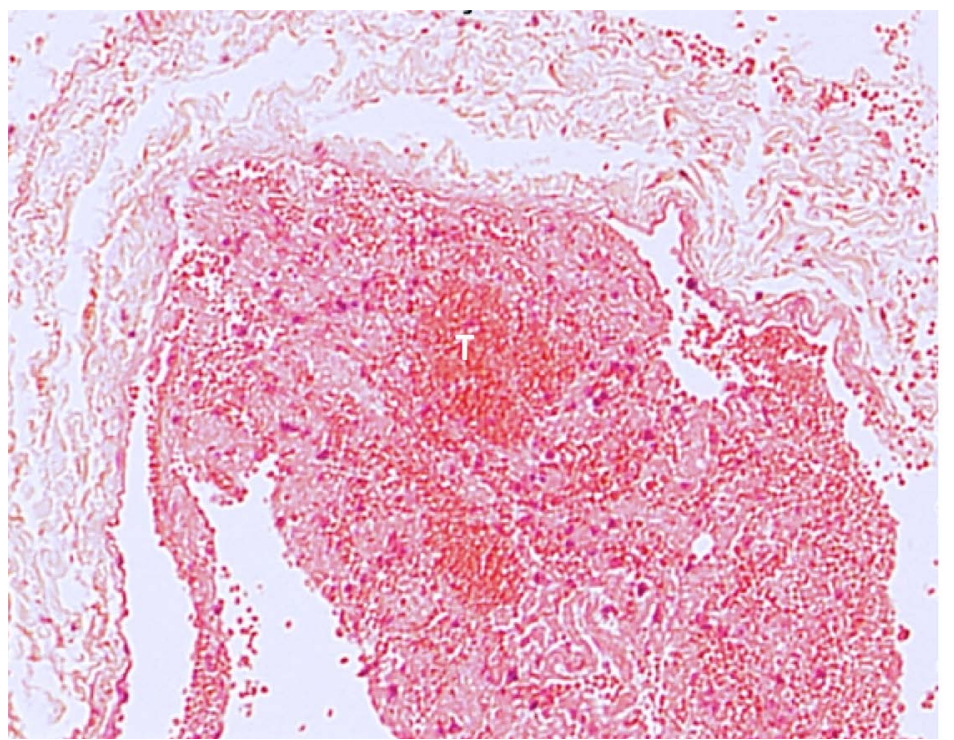

Figure 5. Thrombus (T) formation in the vascular lumen.

of inflammatory process $(p=0.5758)$. Just the same, when comparing the results 
of G2 $\times$ G4 groups in which corticosteroid wasn't used, there was no significant statistical difference regarding the presence of inflammatory process $(p=0.1515)$.

In the comparison of the Groups G1 × G2 in which corticosteroid was used, there was no statistical differences with regards to the presence of inflammatory process $(p=0.7333)$. Just the same, when comparing the results of $\mathrm{G} 3 \times \mathrm{G} 4$ groups in which corticosteroid wasn't used, there was no significant statistical difference regarding the presence of inflammatory process $(p=0.3571)$.

\section{Discussion}

Central venous access, used in several pediatric units and numerous surgical procedures, presents high rates of complications [1] [2].

Endothelial lesion, venous stases, and the condition of blood hypercoagulability lead to thrombophlebitis and DVP [6]. The latter, triggers coagulation reaction in cascade, exposure of subendothelial tissue, activation of tissual thromboplastin, Tumor Necrosis Factor (TNF) and release of interleukin-1 (IL-1) from endothelium cells and toxins released as the result of necrosis or tissual lesion of blood vessels [7] [8]. A high number of thrombophlebitis cases occur after chemical injury of the vase intima by injections or intravenous infusions of different solutions and different concentrations aimed at diagnostic or therapeutic procedures [9]. Mechanical factors concerning venous catheterization are also associated to this process in which catheter material, insertion site and permanence time are variables that should be considered [10].

In thrombophlebitis initial phase, the vein and the thrombus present predominance of leukocytic infiltration (phlogistic). This inflammatory process spreads out to neighboring tissues, especially skin and subcutaneous cellular tissues characterizing edema, erythema and local pain [11] [12].

The use of Betamethasone as an anti-inflammatory agent can act as an inhibitor of pro-inflammatory agents and some interleukins, especially IL-1. The synthetic analogue of the glucocorticoid betamethasone can also be active locally inhibiting the inflammatory reactions described in our previous study [12] [13].

The slight reduction of the inflammatory process frequency in G2 and G4 when compared to G1 and G3 respectively, even if it is not a statistical significant difference, suggests actual decrease tendency of local inflammation, as well as phlebitis and thrombophlebitis.

Despite the lack of significant statistic difference, permanence time differences when G1 and G2 are compared with G3 and G4 respectively, showed that these local inflammatory processes can be auto-limited and decrease in time. In this case, corticosteroid could have acted as a potentiating factor in this improvement which allowed a longer time of catheter permanence.

No local alterations were observed in the G5 animals.

Since the current study was performed by undergraduate students, a small sample was utilized. FCMS Statistic Department suggests that if the samples were enlarged, it would be possible to attain a statistical significant difference.

In conclusion, Betamethasone used at the catheter insertion sites by phlebot- 
omy can influence the manifestation of local inflammatory processes of venous catheterizations.

\section{Acknowledgements}

In appreciation for the Scientific Initiation fellowship granted to the Biologist Luciana Canabarro for her invaluable help with laboratory practices, FCMS/ PUC-SP.

\section{References}

[1] Sastre, J.B.L., Colomer, B.F., Cotallo, G.D.C. and Aparício, A.R. (2000) Estudio prospectivo sobre catéteres epicutáneos en neonatos. Anales de Pediatría, 53, 138- 147. https://doi.org/10.1016/S1695-4033(00)77430-3

[2] Janes, M., Kalyn, A., Pinelli, J. and Paes, B. (2000) A Randomized Trial Comparing Peripherally Inserted Central Venous Catheters and Peripheral Intravenous Catheters in Infants with Very Low Birth Weight. Journal of Pediatric Surgery, 35, 1040-1044. https://doi.org/10.1053/jpsu.2000.7767

[3] Chait, P.G., Temple, M., Connolly, B., John, P., Restrepo, R. and Amaral, J.G. (2002) Pediatric Interventional Venous Access. Techniques in Vascular and Interventional Radiology, 5, 95-102. https://doi.org/10.1053/tvir.2002.36047

[4] Lesher, A.P., Kratz, J.M. and Smith, C.D. (2008) Removal of Embedded Central Venous Catheters. Journal of Pediatric Surgery, 43, 1030-1034.

https://doi.org/10.1016/j.jpedsurg.2008.02.014

[5] Xiang, D.Z., Verbeken, E.K., Van Lommel, A.T.L., Stas, M. and De Wever, I. (1998) Composition and Formation of the Sleeve Enveloping a Central Venous Catheter. Journal of Vascular Surgery, 28, 260-271. https://doi.org/10.1016/S0741-5214(98)70162-4

[6] Romão, R.L.P., Valinetti, E., Tannuri, A.C.A. and Tannuri, U. (2008) Percutaneus Central Venous Catheterization through the External Jugular Vein in Children: Improved Success Rate with Body Maneuvers and Fluoroscopy Assistance. Journal of Pediatric Surgery, 43, 1280-1283. https://doi.org/10.1016/j.jpedsurg.2007.08.052

[7] Cannon, R., Shah, M., Suydan, E., Gucwa, A., Bowden, T., Holsten Jr., S.B. (2008) Early Thrombosis of the Superior Vena Cava in a Patient with a Central Venous Catheter and Carcinoma of the Ampulla of Vater. The American Surgeon, 74, 1195- 1197.

[8] Kumar, V., Abbas, A. and Fausto, N. (2005) Patologia-Bases Patológicas das Doenças. 7th Editon, Elsevier, Rio de Janeiro, 131-142.

[9] Sobreira, M.L., Yoshida, W.B. and Lastória, S. (2008) Superficial Thrombophlebitis: Epidemiology, Physiopathology, Diagnosis and Treatment. Jornal Vascular Brasi- leiro, 7, 131-143.

[10] Singh, R., Bhandary, S. and Pun, K.D. (2008) Peripheral Intravenous Catheter Related Phlebitis and Its Contributing Factors among Adult Population at KU Teaching Hospital. Kathmandu University Medical Journal, 6, 443-447.

[11] Andreozzi, G.M. and Verlato, F. (2000) Tromboflebitis Superficialis. Minerva Cardioangiologica, 48, 9-14.

[12] Rodrigues, B.R., França, G.S., Ferro, M.C., Luciana, C. and França, W.M. (2015) Venous Catheterization Experimental Model in Rabbits: Histological Alterations in the Catheter Region. Surgical Science, 6, 532-540. 
https://doi.org/10.4236/ss.2015.612076

[13] Gonçalves, F.L.L., Bittencourt, D.G., Velloso, L.A., Schmidt, A.F., Gallindo, R.M. and Sbragia, L. (2013) Corticosteroid Effect upon Intestinal and Hepatic Interleukin Profile in a Gastroschisis Rat Model. Acta Cirúrgica Brasileira, 28, 8-12. https://doi.org/10.1590/S0102-86502013001300003

Submit or recommend next manuscript to SCIRP and we will provide best service for you:

Accepting pre-submission inquiries through Email, Facebook, LinkedIn, Twitter, etc. A wide selection of journals (inclusive of 9 subjects, more than 200 journals)

Providing 24-hour high-quality service

User-friendly online submission system

Fair and swift peer-review system

Efficient typesetting and proofreading procedure

Display of the result of downloads and visits, as well as the number of cited articles Maximum dissemination of your research work

Submit your manuscript at: http://papersubmission.scirp.org/

Or contact ss@scirp.org 